\title{
ITGA4 gene methylation status in chronic lymphocytic leukemia
}

\author{
Hanaa RM Attia*,1 (D), Mona Hamed Ibrahim', Shereen H Abd El-Aziz', Naglaa M Hassan², \\ Randa A Osman ${ }^{3}$, Heba A Hagag ${ }^{4}$, Marianne E Yassa ${ }^{5}$, Amany H Abdelrahman 6 , Iman I \\ Salama ${ }^{7}$ \& Mohamed Emam Sobeih ${ }^{8}$ \\ ${ }^{1}$ Clinical \& Chemical Pathology Department, Medical Division, National Research Centre, Centre of Excellence, Cairo, Egypt \\ ${ }^{2}$ Clinical Pathology Department, National Cancer Institute, Cairo University, Cairo, Egypt \\ ${ }^{3}$ Clinical Pathology Department, Flow Cytometry Unit, National Cancer Institute, Cairo University, Cairo, Egypt \\ ${ }^{4}$ Cytogenetic Unit - Main Lab., Kasr Al-Ainy School of Medicine, Cairo University, Cairo, Egypt \\ ${ }^{5}$ Clinical \& Chemical Pathology Department, Kasr Al-Ainy School of Medicine, Cairo University, Cairo, Egypt \\ ${ }^{6}$ Clinical \& Chemical Pathology Department, National Research Centre, Cairo, Egypt \\ ${ }^{7}$ Community Medicine Research Department, National Research Centre, Cairo, Egypt \\ ${ }^{8}$ Medical Oncology Department, National Cancer Institute, Cairo University, Cairo, Egypt \\ *Author for correspondence: Hanarasmy2000@yahoo.com
}

Background: We aimed to investigate ITGA4 gene expression pattern and to explore its methylation heterogeneity in chronic lymphocytic leukemia (CLL). Patients \& methods: Eighty one CLL patients and 75 healthy subjects were enrolled and prognostic evaluation of patients was assessed. ITGA4 q-realtime PCR was performed using Applied Biosystems, TaqMan gene expression assay. ITGA4 gene-specific CpG methylation was investigated in real time using pyrosequencing technology. Results: ITGA4 was differentially expressed in CLL patients. The CpG sites-1, 2 and 3 showed significantly higher mean levels than healthy controls ( $p=<0.001,0.007$ and 0.009). Significant association between CpG site-1 and CLL has been detected using age-adjusted logistic regression $(p<0.001)$. Conclusion: Hypermethylation at ITGA4 gene CpG sites $(1,2,3)$ is a characteristic feature in CLL.

Lay abstract: Chronic lymphocytic leukemia (CLL) is a clonal lymphoproliferative disorder that is characterized by heterogeneous presentation. The ITGA4 gene (CD49d) encodes a member of the integrin alpha chain family of proteins. With this study we aimed to investigate the ITGA4 gene expression by q-realtime PCR and to explore its methylation heterogeneity using pyrosequencing technology in CLL. We found that the ITGA4 gene was differentially expressed in CLL patients. A significant association between CpG site1 and CLL has been detected using age-adjusted logistic regression analysis. Hypermethylation at ITGA4 gene CpG sites $(1,2,3)$ is a characteristic feature in CLL when compared with healthy controls.

First draft submitted: 19 February 2020; Accepted for publication: 22 April 2020; Published online: 26 June 2020

Keywords: beta 2 microglobulin $\bullet$ chronic lymphocytic leukemia $\bullet$ cytogenetics $\bullet$ ITGA4 gene expression $\bullet$ methylation analysis $\bullet$ prognostic markers $\bullet$ pyrosequencing

Chronic lymphocytic leukemia (CLL) is a clonal lymphoproliferative disorder that is characterized by heterogeneous presentation at the clinical and molecular levels. Many investigations into CLL genetics have provided more understanding of CLL biology and a plethora of new prognostic markers have been delivered for predicting patient outcomes and response to chemotherapy or targeted therapy [1-3]. ITGA4 protein has been found to be deregulated in CLL with adverse clinical outcome. ITGA4 gene (CD49d) encodes a member of the integrin alpha chain family of proteins and is considered a negative prognosticator in CLL with aggressive course and short time to treatment [4-7]. It is implicated in B-cell binding to the microenvironment and stromal cells found in the germinal centers of lymphoid follicle. It also serves as a signaling receptor that upregulates BCL-2 transcription, which in turn delivers prosurvival signals, inhibits apoptosis and protects CLL cells from drug-induced damages $[8,9]$. DNA methylation is considered a new approach in CLL genetics to provide diagnostic and prognostic biomarkers for beneficial use in clinical settings. The CLL epigenome shows global hypomethylation and local hypermethylation 
with increased opportunities for somatic mutations [10-12]. The interplay between hypo- and hyper-methylation in the CLL genome highlighted the methylation-dependent role in gene expression deregulation and its impact on malignant transformation and disease progression [13]. ITGA4 overexpression in trisomy 12 CLL patients was proved to be regulated by a methylation dependent mechanism [5]. Altered methylation patterns of promotor regions in the genes have been detected previously and proposed as prognostic markers in CLL [14,15]. Kulis et al. reported that CLL patients with mutated or unmutated IGHV have different epigenetic signature from normal B cell subpopulations using whole-genome bisulfite sequencing and high-density microarrays [15]. In this study we aimed to investigate ITGA4 gene expression pattern and to explore its methylation heterogeneity in CLL. Also, we aimed to identify their association with different well-established prognostic variables that can guide management strategies and targeted therapy.

\section{Patients \& methods}

Eighty one CLL patients and 75 healthy controls were enrolled for the study between 2017 and 2019. Patients were diagnosed according to WHO classification of hemato-lymphoid tumors [16]. The study was approved by ethical committee of National Research Centre (registration number 17-147). All participants gave informed consent before being included in accordance with the code of ethics of the World Medical Association (Declaration of Helsinki) for experiments on humans. Fresh peripheral venous blood samples were withdrawn from patients and controls.

For prognostic evaluation, B2M was analyzed using enzyme-linked immunoassay and CD49d, CD38 and cytoplasmic ZAP-70 were assessed as previously described using Beckman Coulter's Navios Flow Cytometer [17]. The Vysis CLL FISH Probe Kit (List No. 04N02-021, Abbott Molecular, IL, USA) was used to study chromosomes 11, 12, 13 and 17 to determine deletion status of the locus-specific identifier TP53, ATM and D13S319 probe targets and gain of the D12Z3 sequence in fresh heparinized peripheral blood specimens from patients according to manufacturer's instructions [18].

\section{ITGA4 gene expression \& methylation analysis}

Total RNA and genomic DNA were extracted from the fresh EDTA blood samples of each subject of both patients and controls promptly after specimen collection with the RNeasy Mini Kit and a QIAamp DNA Mini Kit (QIAGEN, Strasse 140724 Hilden, Germany), respectively according to the manufacturer's guidelines using automated QiaCube ${ }^{\circledR}$ nucleic acid extractor (QIAGEN). Integrity and quality of the purified RNA and DNA were measured initially in duplicates by NanoDrop 2000c spectrophotometer ${ }^{\circledR}$ (Thermo Fisher Scientific Inc., DE, USA); verified on Qubit ${ }^{\circledR} 2.0$ fluorometer (Invitrogen, Thermo Fisher Scientific Inc., [Life Technologies Holdings Pte Ltd, MA, USA]) using high sensitivity dsDNA and RNA quantitation Kits.

\section{ITGA4 gene expression}

High-capacity cDNA Reverse Transcription Kit (Applied Biosystems, Thermo Fisher Scientific Inc., Vilnius, Lithuania) was employed for c-DNA synthesis according to the manufacturer's guidelines in a total reaction volume of $20 \mathrm{ul}$ with the following thermal profile: $25^{\circ} \mathrm{C}$ for $10 \mathrm{~min} ; 37^{\circ} \mathrm{C}$ for $120 \mathrm{~min} ; 85^{\circ} \mathrm{C}$ for $5 \mathrm{~min}$; finally $4^{\circ} \mathrm{C}$ indefinitely.

ITGA4 gene expression by q-realtime PCR was performed using TaqMan Gene Expression assay, (ID: Hs00168433_m1, cat. no. 4331182), (Applied Biosystems, Thermo Fisher Scientific Inc.) on the QuantStudio 12K flex Real-Time PCR system (Applied Biosystems-Life Technologies, CA, USA). Experiment setup profile was as follows; hold at $50^{\circ} \mathrm{C}$ for $2 \mathrm{~min}$, hold at $95^{\circ} \mathrm{C}$ for $10 \mathrm{~min}$, then PCR stage ( 40 cycles): denature at $95^{\circ} \mathrm{C}$ for $15 \mathrm{~s}$ then anneal/extend at $60^{\circ} \mathrm{C}$ for $1 \mathrm{~min}$. The expressions were quantitated relative to the $B 2 M$ housekeeping gene (ID: Hs00187842_m1) using the $2 \Delta \Delta \mathrm{CT}$ method to calculate the relative expression of ITGA4 gene in the studied samples.

Methylation of the ITGA4 gene (ENSG00000115232, chromosome location chr2. q31.3:182,321,575-182,323,696) with four intronic $C p G$ sites

Genomic DNA was sodium bisulfite modified to selectively convert cytosine to uracil using the QIAGEN EpiTect Fast DNA Bisulfite Kit (cat no. 59824). Bisulfite conversion thermal cycling conditions were as follows: denaturation for $5 \mathrm{~min}$ at $95^{\circ} \mathrm{C}$; incubation for $10 \mathrm{~min}$ at $60^{\circ} \mathrm{C}$; hold indefinitely at $20^{\circ} \mathrm{C}$. Cleanup of converted DNA was done according to the manufacturer's protocol. 
PCR was performed using PyroMark PCR kit from QIAGEN (cat.no: 978703), including primers designed specifically to bisulfite-modified DNA, one of them is biotinylated primer at its $5^{\prime}$ end for pyrosequencing template preparation. Cycling protocol was as follows: initial activation for $15 \mathrm{~min}$ at $95^{\circ} \mathrm{C}$; three step cycling for 45 cycles: denaturation for $30 \mathrm{~s}$ at $94^{\circ} \mathrm{C}$; annealing for $30 \mathrm{~s}$ at $56^{\circ} \mathrm{C}$; extension for $30 \mathrm{~s}$ at $72^{\circ} \mathrm{C}$ then final extension for $10 \mathrm{~min}$ at $72^{\circ} \mathrm{C}$. Then agarose gel verification of amplicon (121 bp) was performed to verify that we have a single, sharp band and no unincorporated primers.

Pyrosequencing analysis: ITGA4 CpG assay Kit (Hs_ITGA4_01_PM PyroMark CpG assay, cat no. PM00097489, QIAGEN) was used for ITGA4 gene-specific CpG methylation in real time using pyrosequencing technology on the PyroMark Q24 System with software v.2.0. The kit includes $10 \times$ PCR primer set and $10 \times$ sequencing primers. Four CpG dinucleotide pairs (sites) were analyzed.

Analyzed sequence was: CGGCGTGAGAATGGCGCCCTAGGGATTCCCTGCCCGA and the nucleotide dispensation order was set according to the manufacturer's instructions: GTCGTCGATGAGATAGTCGTTAGAGTTGTCG.

\section{Statistical methods}

Data were coded and entered using the statistical package for the Social Sciences (SPSS) version 25 (IBM Corp., NY, USA). Data were summarized using mean, standard error of the mean, minimum and maximum in quantitative data and using frequency (count) and relative frequency (percentage) for categorical data. Comparisons between quantitative variables were done using t-test and for the nonparametric data Kruskal-Wallis and Mann-Whitney tests were used [19]. One sample Wilcoxon signed rank test was used to test for gene fold change significance. For comparing categorical data, Chi square $\left(\chi^{2}\right)$ test was performed. Exact test was used instead when the expected frequency is less than 5 [20]. Correlations between quantitative variables were done using Spearman correlation coefficient. p-values less than 0.05 were considered as statistically significant.

\section{Results}

Demographic, clinical and laboratory findings of CLL patients and controls are presented in Table 1. ITGA4 was differentially expressed in CLL patients with mean fold change of $1.463 \pm 0.11$ and $\mathrm{p}<0.001$. No statistical difference in the ITGA4 gene expression mean fold change has been observed in patients with different Binet stage or disease course whether indolent or aggressive ( $\mathrm{p}=0.417$ and 0.319 , respectively). CLL patients were categorized according to ITGA4 fold change into two groups. Upregulated expression of ITGA4 more than 1.5-fold change was detected in $46.9 \%$ of all patients. A subset of CLL patients presented with low expression of ITGA4 gene (24.69\%). Both groups were age and sex matched. Laboratory variables in different patient categories based on ITGA4 fold change are demonstrated in Table 2. Lymphadenopathy was detected in $72.8 \%$ of CLL patients and observed more in the high ITGA4 expression subset of CLL patients with $\mathrm{p}=0.026$. Higher mean expression percentage of ITGA4 protein by flowcytometry and trisomy 12 were observed in patients with upregulated gene when compared with patients with downregulated gene ( $\mathrm{p}=0.001$ and 0.046 , respectively). No significant difference was detected in the mean levels of expression percentage of CD38, ZAP-70, del17p, del11q and del13q between both upregulated and downregulated gene groups.

Methylation analysis of ITGA4 gene (four intronic CpG sites) was performed with GeneGlobe specification, presented in Figure 1 [21]. Methylation pyrogram of some CLL patients is shown in Figure 2. Comparison between ITGA4 gene methylation (\%) of the four CpG sites between CLL patients and controls is demonstrated in Table 1 \& Figure 3. The CpG sites-1, 2 and 3 showed significantly higher mean levels in CLL patients than healthy controls ( $\mathrm{p}<0.001,0.007$ and 0.009 , respectively). By comparing the mean methylation \% of the four CpG sites in different patient categories based on ITGA4 gene expression fold change, CpG sites-1 and 2 showed significantly higher mean methylation $\%$ in patients with downregulated gene than patients with upregulated gene, $(p=0.029$ and 0.01 , respectively) as shown in Table 2.

Receiver operating characteristic analysis was done for the four CpG sites to discriminate between CLL patients and healthy controls (Figure 4). Cut-off values were established for CLL diagnostic and prognostic evaluation (Table 3). The frequency of ITGA4 hypermethylation of the significant CpG sites among patients and controls is presented in Table 4.

Based on cytogenetics findings, patients were stratified to identify the differences in the ITGA4 CpG sites. Patients with del13q14+ expression showed significant increase in the mean methylation levels of CpG site-2 $($ mean $\pm \mathrm{SE} ; 4.1 \pm 0.57$ vs $2.7 \pm 0.15 ; \mathrm{p}=0.015)$ and $\mathrm{CpG}$ site-3 (mean $\pm \mathrm{SE} ; 4.6 \pm 0.6$ vs $3.4 \pm 0.2 ; \mathrm{p}=0.029)$. 


\begin{tabular}{|c|c|c|c|}
\hline Character & CLL patients $(n=81)$ & Controls $(n=75)$ & p-value \\
\hline $\begin{array}{l}\text { Gender } \\
\text { - Males, n (\%) } \\
\text { - Females, n (\%) }\end{array}$ & $\begin{array}{l}47(58.02) \\
34(41.98)\end{array}$ & $\begin{array}{l}46(61.33) \\
29(38.67)\end{array}$ & 0.362 (NS) \\
\hline Age (years), mean \pm standard deviation & $58.25 \pm 9.67$ & $51.18 \pm 7.0$ & 0.125 (NS) \\
\hline $\begin{array}{l}\text { Course of disease: } \\
\text { - Newly diagnosed, n (\%) } \\
\text { - Indolent, n (\%) } \\
\text { - Aggressive, n (\%) }\end{array}$ & $\begin{array}{l}0(12.35) \\
32(39.51) \\
39(48.14)\end{array}$ & - & - \\
\hline $\begin{array}{l}\text { Staging (Binet) at diagnosis, } \\
\text { - Stage A, n (\%) } \\
\text { - Stage } B, n(\%) \\
\text { - Stage } C, n(\%)\end{array}$ & $\begin{array}{l}11(13.6) \\
29(35.8) \\
41(50.6)\end{array}$ & - & - \\
\hline Family history of leukemia or other types of cancer, $\mathrm{n}(\%)$ & $14(17.3)$ & $6(8)$ & $0.000^{\ddagger}$ \\
\hline Smoking, n (\%) & $24(29.6)$ & $15(20)$ & 0.073 (NS) \\
\hline $\begin{array}{l}\text { Clinical findings: } \\
\text { - Lymphadenopathy, n (\%) } \\
\text { - Splenomegaly, n (\%) } \\
\text { - Hepatomegaly, n (\%) }\end{array}$ & $\begin{array}{l}59(72.8) \\
56(69.1) \\
34(41.9)\end{array}$ & - & \\
\hline $\begin{array}{l}\text { ITGA4 gene regulation } \\
\text { - Downregulated }<0.5 \text {-fold } \\
\text { - Upregulated }>1.5 \text {-fold }\end{array}$ & $\begin{array}{l}20(24.7) \\
38(46.9)\end{array}$ & $\begin{array}{l}3(4.0) \\
29(38.7)\end{array}$ & $0.034^{\dagger}$ \\
\hline $\begin{array}{l}\text { ITGA4 gene methylation } \% \\
- \text { CpG site- } 1 \%(\text { mean } \pm \text { SE) } \\
- \text { CpG site- } 2 \% \text { (mean } \pm \text { SE) } \\
- \text { CpG site- } 3 \%(\text { mean } \pm \text { SE) } \\
- \text { CpG site- } 4 \%(\text { mean } \pm \text { SE })\end{array}$ & $\begin{array}{l}26.9 \pm 0.93 \\
2.9 \pm 0.16 \\
3.7 \pm 0.19 \\
7.6 \pm 0.28\end{array}$ & $\begin{array}{l}7.4 \pm 0.49 \\
2.1 \pm 0.2 \\
2.9 \pm 0.0 .2 \\
6.9 \pm 0.26\end{array}$ & $\begin{array}{l}<0.001^{\ddagger} \\
0.007^{\ddagger} \\
0.009^{\ddagger} \\
0.149\end{array}$ \\
\hline
\end{tabular}

\begin{tabular}{|c|c|c|c|}
\hline Variables & $\begin{array}{l}\text { ITGA4 } \\
<0.5 \text {-fold change CLL patients } \\
(\mathrm{n}=20)\end{array}$ & $\begin{array}{l}\text { ITGA4 } \\
>1.5 \text {-fold change } \\
\text { CLL patients } \\
(\mathrm{n}=38)\end{array}$ & p-value \\
\hline $\begin{array}{l}\text { Gender } \\
\text { - Males, n (\%) } \\
\text { - Females, n (\%) }\end{array}$ & $\begin{array}{l}14(70) \\
6(30)\end{array}$ & $\begin{array}{l}20(52.6) \\
18(47.4)\end{array}$ & 0.250 (NS) \\
\hline Age (years), (mean $\pm \mathrm{SE}$ ) & $58.2 \pm 2.9$ & $57.3 \pm 1.7$ & 0.797 (NS) \\
\hline B2M $(\mu \mathrm{g} / \mathrm{ml}),($ mean $\pm \mathrm{SE})$ & $4.7 \pm 0.69$ & $5.8 \pm 0.55$ & 0.268 (NS) \\
\hline ITGA4 protein expression $\%($ mean \pm SE) & $4.4 \pm 2.3$ & $20.8 \pm 4.8$ & $0.001^{\ddagger}$ \\
\hline CD38 \% (mean \pm SE) & $21.6 \pm 7.3$ & $13.9 \pm 2.7$ & 0.334 (NS) \\
\hline ZAP-70 $\%($ mean \pm SE) & $1.9 \pm 1.3$ & $5.1 \pm 2.2$ & 0.353 (NS) \\
\hline Trisomy $12 \%($ mean $\pm \mathrm{SE})$ & $2.14 \pm 0.376$ & $9.08 \pm 3.3$ & $0.046^{\dagger}$ \\
\hline Del17p \% (mean \pm SE) & $3.14 \pm 0.619$ & $2.58 \pm 0.3$ & 0.358 (NS) \\
\hline Del11q \% (mean $\pm \mathrm{SE})$ & $16.86 \pm 8.5$ & $7.0 \pm 3.3$ & 0.297 (NS) \\
\hline Del13q14 \% (mean \pm SE) & $31.7 \pm 9.3$ & $7.9 \pm 3.7$ & 0.079 (NS) \\
\hline \multicolumn{4}{|l|}{ ITGA4 gene methylation } \\
\hline - CpG site-1 \% (mean \pm SE) & $31.1 \pm 2.0$ & $25.4 \pm 1.4$ & $0.029^{\dagger}$ \\
\hline - CpG site-2 \% (mean \pm SE) & $3.9 \pm 0.5$ & $2.5 \pm 0.157$ & $0.01^{\dagger}$ \\
\hline - CpG site-3 \% (mean \pm SE) & $4.3 \pm 0.57$ & $3.4 \pm 0.25$ & 0.088 (NS) \\
\hline - CpG site- $4 \%($ mean \pm SE) & $8.1 \pm 0.76$ & $7.3 \pm 0.3200$ & 0.347 (NS) \\
\hline
\end{tabular}




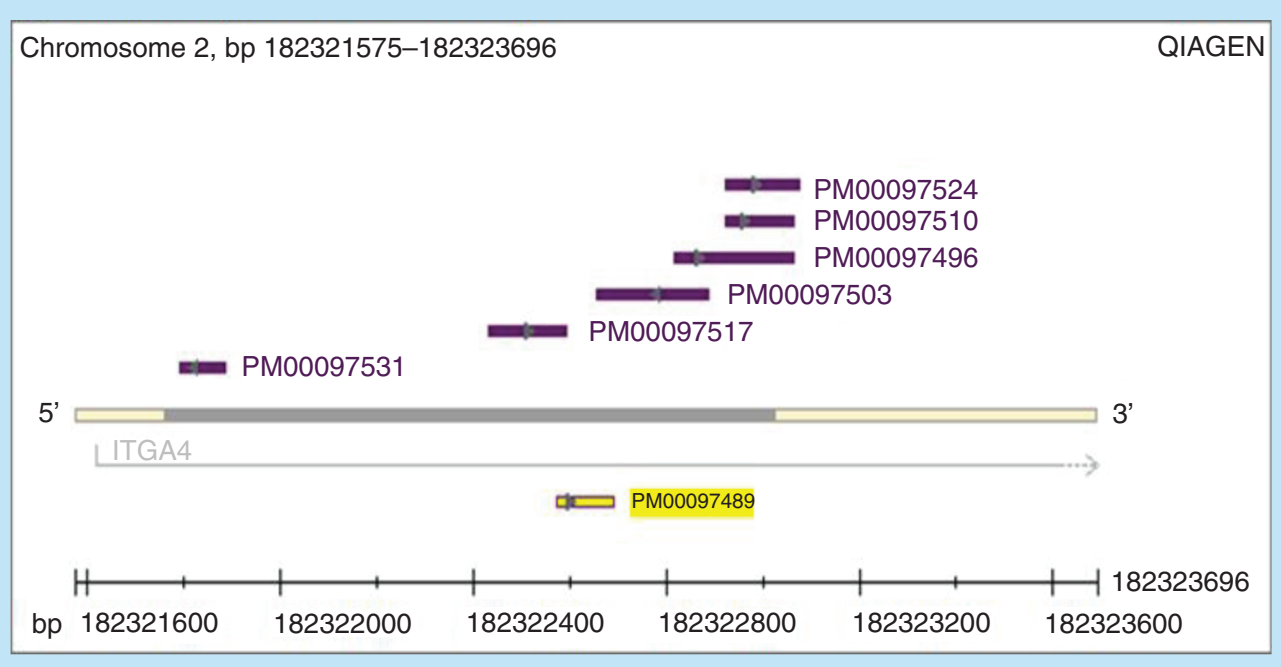

Figure 1. ITGA4; genomic location. ITGA4 gene specification and chromosome location according to GeneGlobe specification, [21].

Table 3. Cut-off values of ITGA4 methylation \% of the four CpG sites for chronic lymphocytic leukemia diagnostic and prognostic evaluation.

\begin{tabular}{|c|c|c|c|c|c|c|}
\hline Variables & Cutoff \% & Sensitivity \% & Specificity \% & AUC & $95 \% \mathrm{Cl}$ & p-value \\
\hline CpG site-1 & 12.5 & 98.6 & 95.8 & 0.998 & $0.994-1.002$ & $<0.001^{\ddagger}$ \\
\hline CpG site-2 & 2.5 & 56.5 & 79.2 & 0.713 & $0.597-0.829$ & $0.002^{\ddagger}$ \\
\hline CpG site-3 & 3.5 & 52.2 & 79.2 & 0.652 & $0.532-0.771$ & $0.028^{\dagger}$ \\
\hline CpG site-4 & 7.5 & 49.3 & 75.0 & 0.612 & $0.488-0.736$ & 0.102 \\
\hline
\end{tabular}

$\dagger_{p}<0.05$ is considered significant.

$\ddagger p<0.01$ is considered highly significant.

AUC: Area under the curve.

Table 4. Frequency of ITGA4 hypermethylation of the significant CpG sites among patients and controls.

ITGA4 gene methylation \% of

CLL patients, number (\%)

Controls, number (\%)

Odds ratio $(95 \% \mathrm{Cl})$

CpG sites

CpG site-1 >12.5\%

80 (98.7)

3 (4)

23.6 (3.47-161.1)

Chi-square significance

CpG site-2 $>2.5 \%$

46 (56.8)

16 (21.3)

$1.448(1.131-1.853)$

(p-value)

CpG site-3>3.5\%

$42(51.8)$

$16(21.3)$

1.384 (1.093-1.751)

$<0.001^{\dagger}$

$0.004^{\ddagger}$

$\dagger_{p}<0.05$ is considered significant;

$\ddagger p<0.01$ is considered highly significant.

CLL: Chronic lymphocytic leukemia.

Furthermore, patients were categorized according to B2M levels to investigate methylation status of ITGA4 CpG sites in both high and low levels of B2M and statistical comparison was performed (Table 5 \& Figure 5).

'Correlation analysis' between ITGA4 gene expression at mRNA level and ITGA4 protein levels defined as mean fluorescent intensity by flow cytometry revealed significant relationship $(\mathrm{r}=0.350 ; \mathrm{p}=0.004)$. CpG site- 1 was correlated significantly to age $(r=0.284 ; \mathrm{p}=0.041)$. Age-adjusted logistic regression was performed and significant association between CpG site-1 and CLL has been detected ( $\mathrm{p}<0.001$ ). Inverse correlations between CpG site-2 and ITGA4 fold change $(\mathrm{r}=-0.342, \mathrm{p}=0.004)$ and between methylation levels at CpG sites-1, 2 and 3 and B2M levels were detected $(\mathrm{r}=-0.421 ; \mathrm{p}<.001 ; \mathrm{r}=-0.373, \mathrm{p}=0.002 ; \mathrm{r}=-0.349 ; \mathrm{p}=0.003$, respectively). Inverse correlations were observed between methylation levels at CpG sites-1 $(r=-0.471 ; p=0.01)$ and CpG site-4 $(r=$ -0.456; $\mathrm{p}=0.015$ ) and CD38 expression levels in the subset of patients with upregulated gene. 


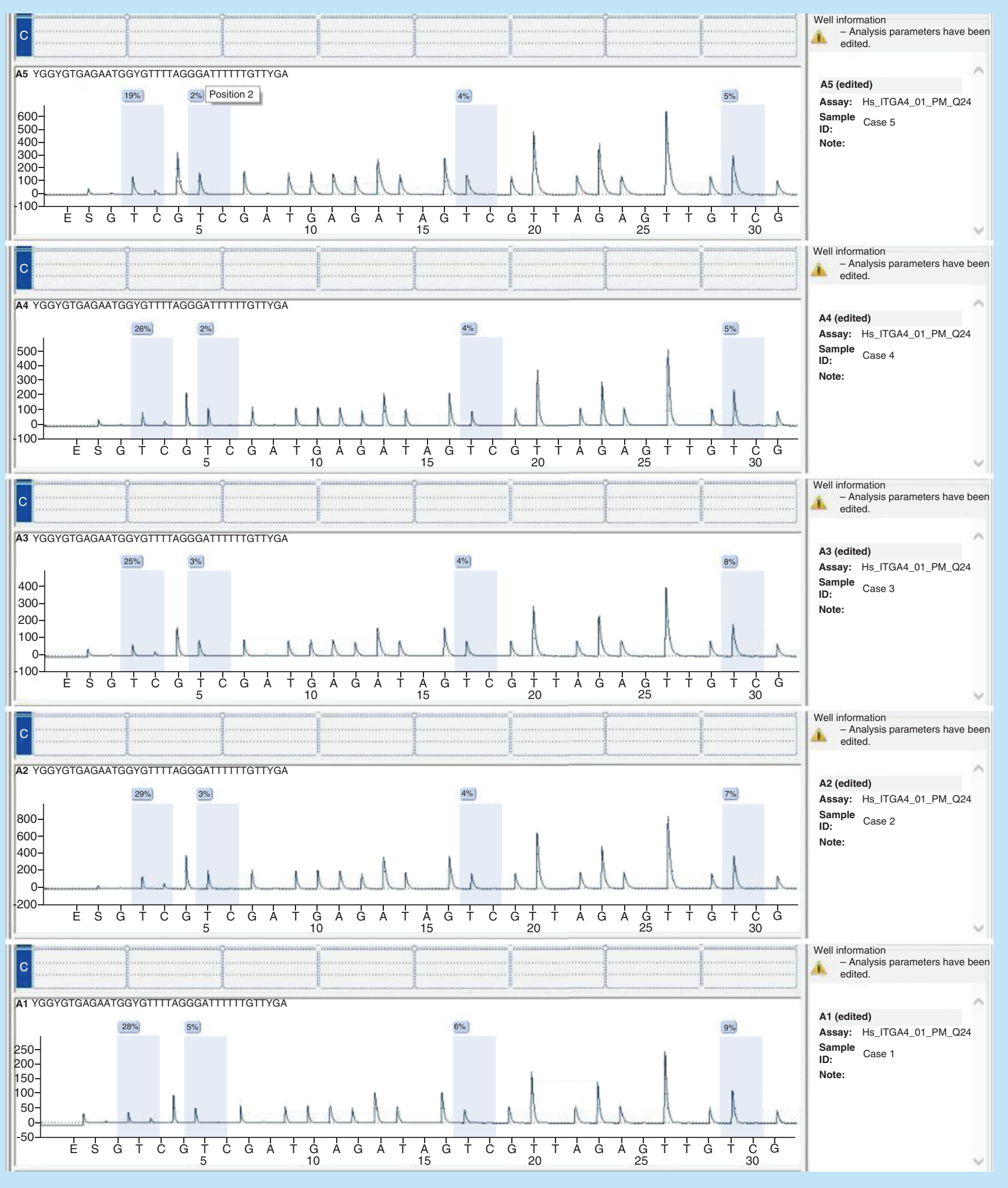

Figure 2. ITGA4 gene methylation (\%) of the four CpG sites by pyrosequencing of some chronic lymphocytic leukemia patients. 


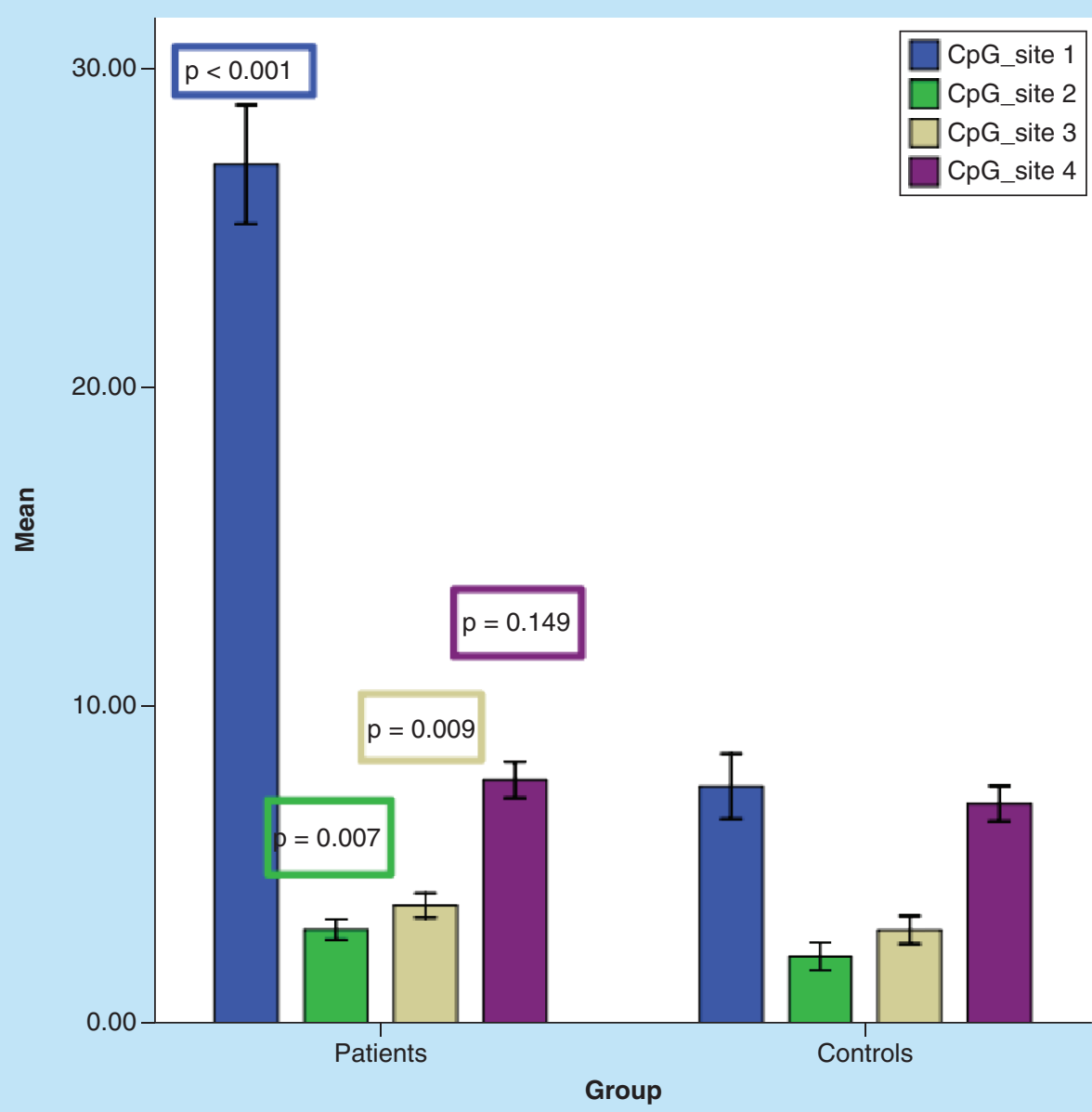

Figure 3. Comparison between ITGA4 gene methylation (\%) of the four CpG sites by pyrosequencing between chronic lymphocytic leukemia patients $(\mathbf{n}=\mathbf{8 1})$ and controls $(\mathbf{n}=\mathbf{7 5})$. The CpG sites-1,2,3 showed significantly higher mean levels in chronic lymphocytic leukemia patients than healthy controls $(p=<0.001,0.007$ and 0.009 , respectively). Error bars: $95 \% \mathrm{Cl}$.

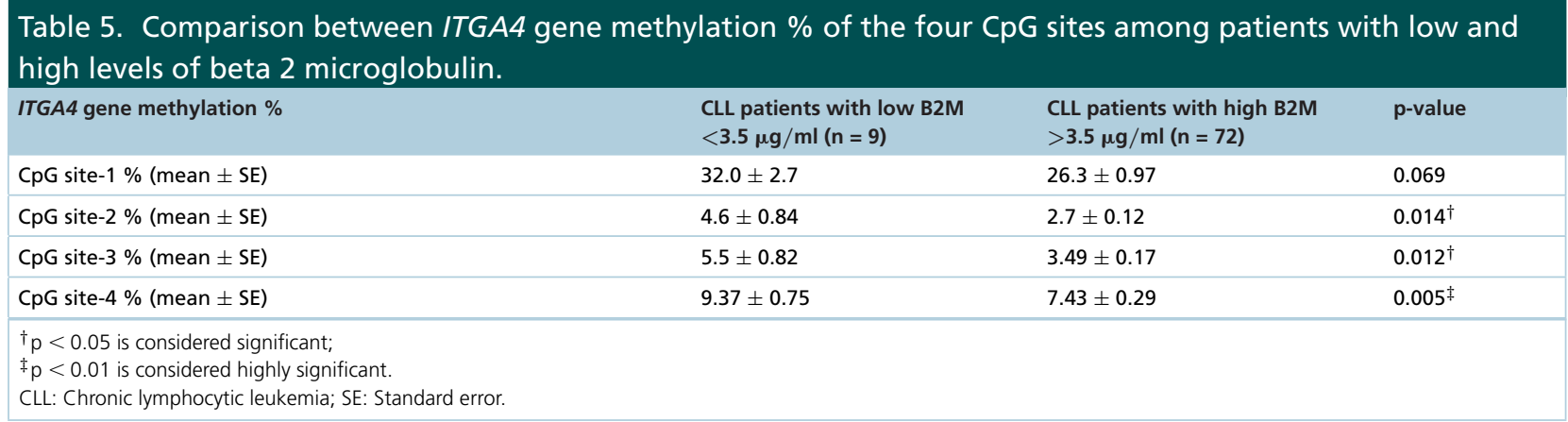

\section{Discussion}

In the present study, deregulated ITGA4 gene investigated by q-real-time PCR was more frequently encountered in CLL patients than their healthy counterparts. ITGA4 protein showed higher mean expression by flow cytometry in patients with upregulated gene at mRNA level. Also, a significant correlation has been detected between ITGA4 gene fold change and ITGA4 protein levels indicating its regulatory role at the level of transcription as previously 


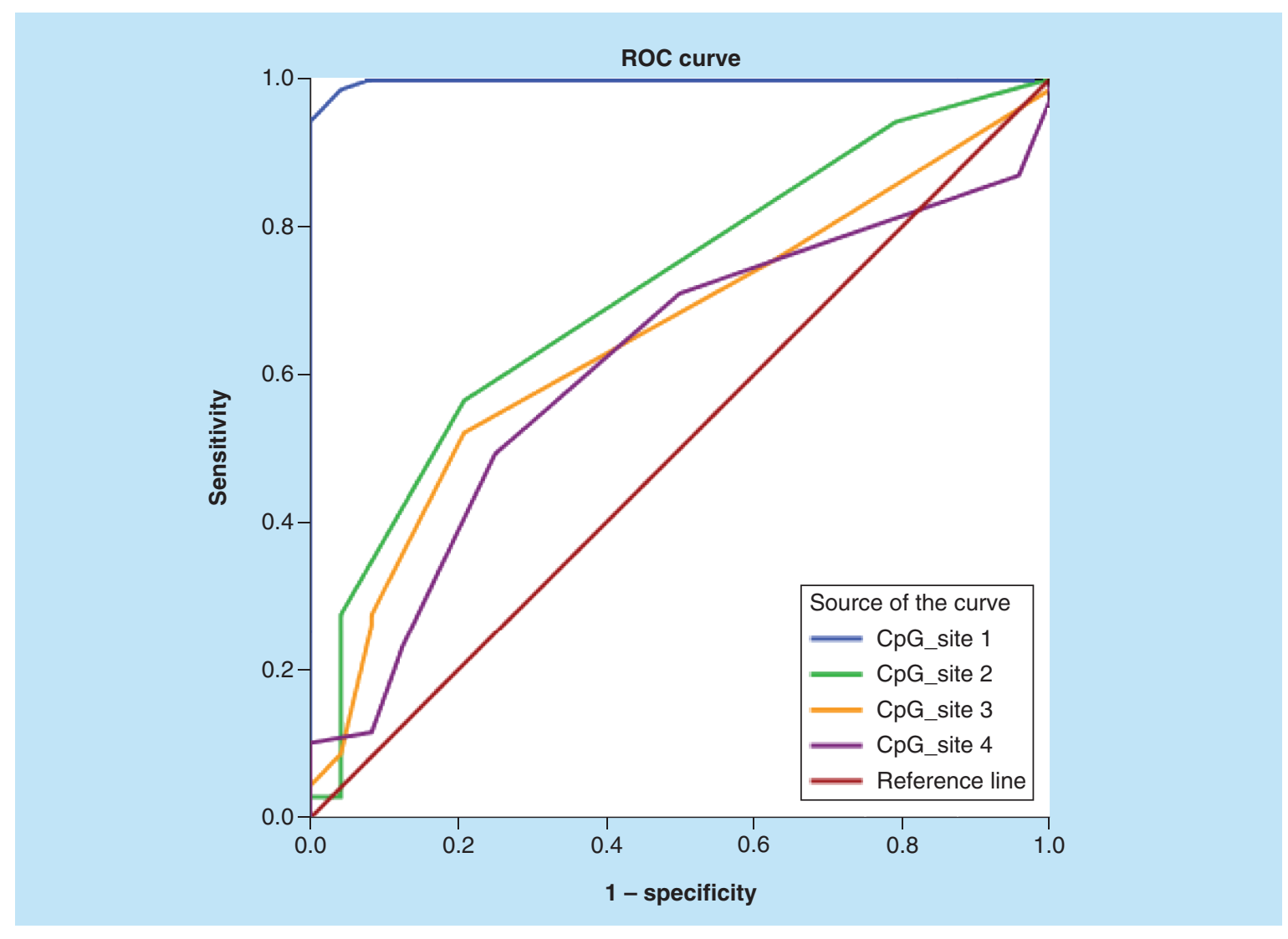

Figure 4. Receiver operating characteristics curves for the ITGA4 methylation $\%$ of the four CpG sites among patients and healthy controls.

ROC: Receiver operating characteristics.

observed by Zucchetto et al. [5]. In patients with upregulated gene, nodal presentation was more frequently observed and mean expression of trisomy 12 with intermediate prognostic features was higher than those with downregulation which are consistent with previous flowcytometry based studies [5-7,22].

A subset of our patients showed low expression of ITGA4 gene which is concordant with previous investigators [23]. Differential gene expression profiles can result from aberrant methylation status that can affect genome stability [13]. To explore the impact of methylation status on heterogeneity in ITGA4 gene expression, analysis of individual CpG sites in the gene has been investigated and the potential role of their variable levels has been established. The methylation analysis demonstrated that CpG sites- 1 and 2 mean levels were elevated in patients with downregulated ITGA4 gene and inverse correlation was observed between CpG site- 2 and ITGA4 fold change. Furthermore, CLL patients displayed highly significant increase in the means of methylation \% of the CpG sites-1, 2 and 3 with more frequent hypermethylation \% of the three $\mathrm{CpG}$ sites than that detected in their healthy counterparts. Global DNA hypomethylation across the genome has been previously considered a characteristic feature in cancer, whereas DNA hypermethylation was more frequently locally observed [24]. Locally aberrant methylation has been previously described in CLL cells when compared with normal CD19 ${ }^{+} \mathrm{B}$ cells and has the potential for gene silencing and inactivation of genes related to normal tissue homeostasis $[13,25]$. Certain introns are considered primary elements directing the gene regulation and causing high gene expression in the genome [26]. So, aberrant methylation of intronic $\mathrm{CpG}$ dinucleotides can affect the expression of the gene with possible prognostic impact.

To identify the association between aberrant methylation of the gene with established prognostic markers, patients were categorized based on cytogenetics findings and B2M levels and comparisons have been investigated. High mean levels of $\mathrm{CpG}$ sites 2 and 3 were observed in patients with positive expression of del13q14. Furthermore, in the context of high B2M levels, lower mean levels of methylated $\mathrm{CpG}$ sites have been observed. Inverse correlations between methylation levels at CpG sites-1, 2 and 3 and B2M levels were detected. These findings postulated a 


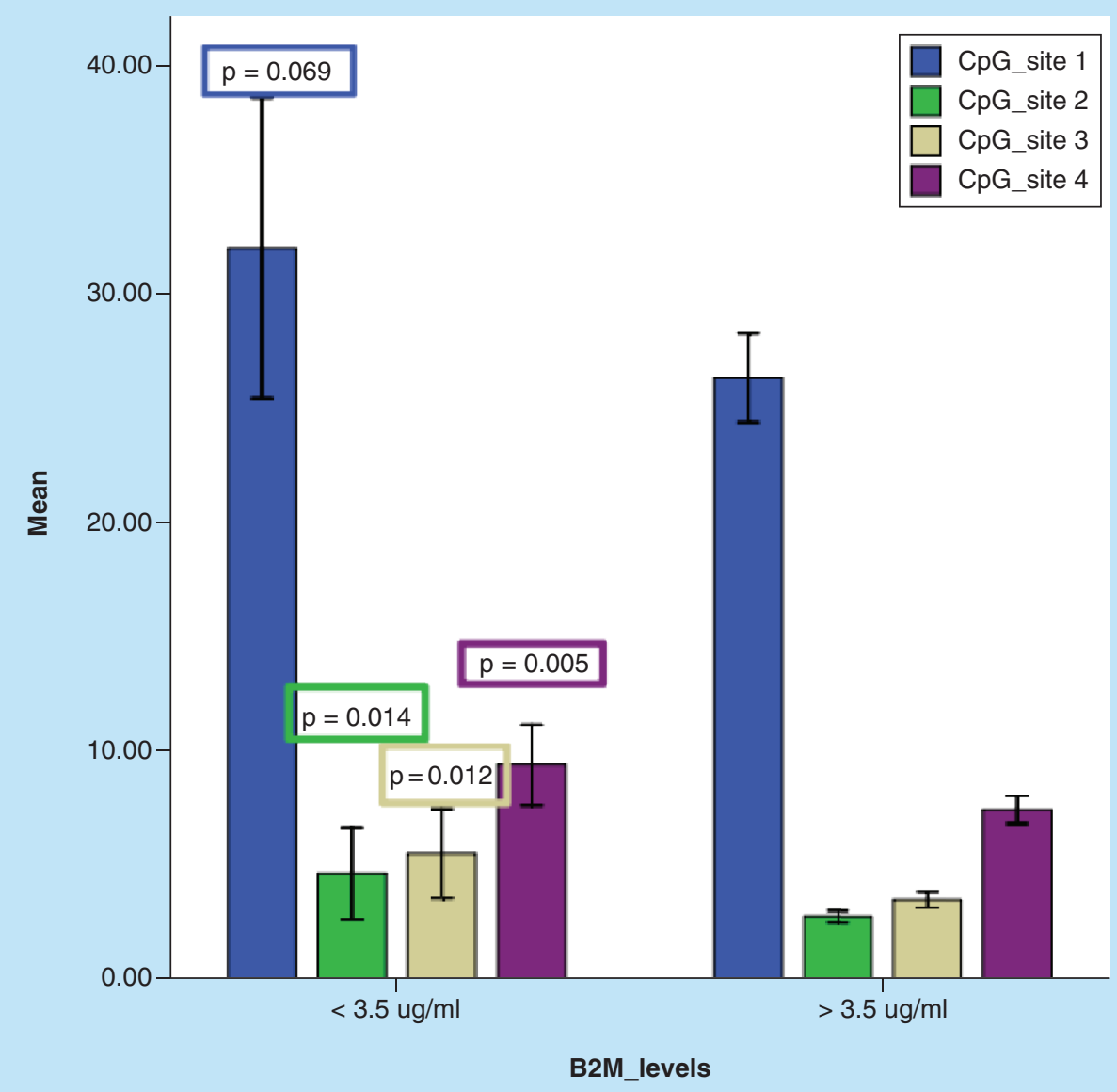

Figure 5. Comparison between ITGA4 gene methylation (\%) of the four CpG sites by pyrosequencing between different groups of chronic lymphocytic leukemia patients based on B2M levels (patients with B2M $>3.5 \mu \mathrm{g} / \mathrm{ml}$, $\mathrm{n}=62$; patients with $\mathrm{B} 2 \mathrm{M}<3.5 \mu \mathrm{g} / \mathrm{ml}, \mathrm{n}=19$ ).

Error bars: $95 \% \mathrm{Cl}$.

possible favorable impact of hypermethylated ITGA4 gene identified sites on CLL prognosis. In a previous study, stability of DNA methylation has been reported throughout the course of CLL and in relation to therapy while methylation heterogeneity has been found in more aggressive CLL subgroups [27].

In this study, CPG site-1 was significantly correlated to age. Many investigators suggested that a low level of de novo methylation of $\mathrm{CpG}$ islands can take place in normal tissues and increase with age. They postulated that DNA methylation increases with age at some CpG islands and may develop from a small population of cells [28-30]. Age-adjusted logistic regression analysis revealed highly significant association between CPG site 1 and CLL which means that its aberration is related to the disease pathology itself and at a lower level to the aging process.

\section{Conclusion}

In CLL, ITGA4 protein expression is regulated at mRNA level and through local methylation-based mechanism. Methylation status of ITGA4 gene revealed the significance of measuring CpG site 1 as a prognostic marker for CLL and can be a target for therapy. Hypermethylation at certain identified ITGA4 gene CpG sites-1, 2 and 3 is a characteristic feature in CLL. CpG sites-2 and 3 mean methylation levels significantly increased in del13q14+ subset of CLL patients. Also CpG sites-1, 2 and 3 were inversely correlated to B2M levels indicating their prognostic impact for further wide scale studies. 


\section{Future perspective}

Detailed methylation analysis of different individual CpG sites within the ITGA4 gene CpG island is recommended to help more understanding of gene regulation in CLL and aiding in future therapeutic trials. Relation to clinical outcome and overall survival with assessment of other strong prognosticators like the IGHV mutational status as well as mutations of TP53, NOTCH1 and SF3B1 are recommended in further studies.

\section{Summary points}

Aim

- In the current study, we aimed to investigate ITGA4 gene expression pattern and to explore its methylation heterogeneity in chronic lymphocytic leukemia (CLL) that can guide management strategies and targeted therapy.

Patients \& methods

- Eighty one Egyptian CLL patients and 75 healthy subjects were enrolled for the study.

- CD49d, CD38 and ZAP-70 were assessed using flow cytometer.

- FISH technique was performed for detection of del17p, del11q, del13q14 and trisomy 12.

- B2M was measured by ELISA.

- ITGA4 gene expression by q-realtime PCR was performed using Applied Biosystems, TaqMan Gene Expression assay and relative quantitation was performed relative to the B2M housekeeping gene.

- ITGA4 gene-specific CpG methylation in real time using pyrosequencing technology on the PyroMark Q24 System was investigated.

Results

- ITGA4 was differentially expressed in CLL patients (mean fold change of $1.463 \pm 0.11$ and $p<0.001$ ).

- Upregulated expression was detected in $46.9 \%$ of patients. A subset of patients $(24.69 \%)$ displayed low expression of the gene.

- In methylation analysis, the CPG sites-1,2,3 showed significantly higher mean levels than healthy controls ( $p=<0.001,0.007$ and 0.009 , respectively). CpG sites- 1 and 2 showed significantly increased methylation $\%$ in patients with downregulated gene, $(p=0.029$ and 0.01 , respectively).

- Significant association between CPG site-1 and CLL has been detected using age-adjusted logistic regression $(p<0.001)$.

- Mean methylation levels of CPG sites-2 and 3 significantly increased in del13q14+ subset of CLL patients.

- Inverse correlations between methylation \% at CPG sites-1,2,3 and B2M levels were detected.

Conclusion

- In CLL, ITGA4 protein expression is regulated at mRNA level and through local methylation-based mechanism.

- Methylation status of ITGA4 gene revealed the significance of measuring CpG site 1 as a prognostic marker for CLL and can be a target for therapy.

- Hypermethylation at certain identified ITGA4 gene CpG sites-1, 2 and 3 is a characteristic feature in CLL.

- CPG sites-1, 2 and 3 have prognostic impact for further wide scale studies.

Author contributions

HRM Attia and $\mathrm{AH}$ Abdelrahman contributed to the project preparation, study design and submission for funding. $\mathrm{MH}$ Ibrahim was responsible for material preparation, coordinating specimen collection, transport and ensuring a quality policy throughout laboratory analysis workflow. MH Ibrahim and SHA El-Aziz contributed to serological, molecular studies, pyrosequencing analysis and final results' tabulation. FISH technique was performed by HA Hagag and ME Yassa. Flow cytometric analysis was performed by RA Osman. Patient's selection and data collection were fulfilled by NM Hassan, ME Sobeih. HRM Attia and IS Salama contributed to data analysis. Preparation of the first draft of the manuscript and submission was performed by HRM Attia.

\section{Acknowledgments}

The authors would like to appreciate the great help provided throughout the project by MAA Sayed, Assistant researcher, Medical Biochemistry Department, National Research Centre.

Financial \& competing interests disclosure

The authors gratefully acknowledge the financial support of the Science and Technology Development Fund (STDF), Egypt through Targeted Health call grant no. 22918 and Capacity Building Grant no. 4880. The authors have no other relevant affiliations or financial involvement with any organization or entity with a financial interest in or financial conflict with the subject matter or materials discussed in the manuscript apart from those disclosed.

No writing assistance was utilized in the production of this manuscript. 
Ethical conduct of research

All participants gave informed consent before being included in the study in accordance with the code of ethics of the World Medical Association (Declaration of Helsinki) for experiments on humans and the study was approved by ethical committee of National Research Center (registration number 17-147).

\section{Open access}

This work is licensed under the Creative Commons Attribution 4.0 License. To view a copy of this license, visit http://creativecommons.org/licenses/by/4.0/

\section{References}

Papers of special note have been highlighted as: $\bullet$ of interest

1. Stilgenbauer S, Schnaiter A, Paschka P et al. Gene mutations and treatment outcome in chronic lymphocytic leukemia: results from the CLL8 trial. Blood 123(21), 3247-3254 (2014).

2. Landau DA, Tausch E, Taylor-Weiner AN et al. Mutations driving CLL and their evolution in progression and relapse. Nature 526, 525-530 (2015).

3. Rassenti LZ, Huynh L, Toy TL et al. ZAP-70 compared with immunoglobulin heavy-chain gene mutation status as a predictor of disease progression in chronic lymphocytic leukemia. N. Engl. J. Med. 351(9), 893-901 (2004).

4. Bulian P, Shanafelt TD, Fegan C et al. CD49d is the strongest flow cytometry-based predictor of overall survival in chronic lymphocytic leukemia. J. Clin. Oncol. 32(9), 897-904 (2014).

- In this analysis of approximately 3000 patients with chronic lymphocytic leukemia (CLL), authors identified CD49d as the strongest flow cytometry-based predictor of overall survival (OS) and treatment-free survival (TFS) independent of CD38 and ZAP-70.

5. Zucchetto A, Caldana C, Benedetti D et al. CD 49d is overexpressed by trisomy 12 chronic lymphocytic leukemia cells: evidence for methylation-dependent regulation mechanism. Blood 122(19), 3317-3321 (2013).

- Authors demonstrated that CD49 is universally expressed in Trisomy12 CLL and is regulated by a methylation-dependent mechanism

6. Zucchetto A, Vaisitti T, Benedetti D et al. The CD49d/CD29 complex is physically and functionally associated with CD38 in B-cell chronic lymphocytic leukemia cells. Leukemia 26, 1301-1312 (2012).

- Authors studied the role of CD38 in CD49d-mediated cell adhesion and provided an explanation for the negative clinical impact exerted by CD49 and CD38 when coexpressed in CLL cells.

7. Uzay A, Toptas T, Kaygusuz I et al. The prognostic value of CD49d expression in Turkish patients with chronic lymphocytic leukemia. Turk. J. Hematol. 29, 354-360 (2012).

8. Dal Bo M, Tissino E, Benedetti D et al. Microenvironmental interactions in chronic lymphocytic leukemia: the master role of CD49d. Semin. Hematol. 51, 168-176 (2014).

- This article addresses CD49d activities in the CLL microenvironment, its interactions with CD38 and B-cell receptor.

9. Dal Bo M, Tissino E, Benedetti D et al. Functional and clinical significance of the integrin alpha chain CD49d expression in chronic lymphocytic leukemia. Curr. Cancer Drug Targets 16, 659-668 (2016).

10. Cahill N, Bergh AC, Kanduri M et al. 450K-array analysis of chronic lymphocytic leukemia cells reveals global DNA methylation to be relatively stable over time and similar in resting and proliferative compartments. Leukemia 27, 150-158 (2013).

11. Ziller MJ, Gu H, Müller F et al. Charting a dynamic DNA methylation landscape of the human genome. Nature 500, 477-481 (2013).

12. Kipps TJ, Stevenson FK, Wu CJ et al. Chronic lymphocytic leukaemia. Nat. Rev. Dis. Primers 3, 16096 (2017).

13. Corcoran M, Parker A, Orchard J et al. ZAP-70 methylation status is associated with ZAP-70 expression status in chronic lymphocytic leukemia. Haematologica 90, 1078-1088 (2005).

- Authors measured ZAP-70 methylation status in CLL for predicting prognosis and detected its close association with ZAP-70 expression and IgVH gene mutational status.

14. Chantepie SP, Vaur D, Grunau C et al. ZAP-70 intron1 DNA methylation status: determination by pyrosequencing in B chronic lymphocytic leukemia. Leukemia Res. 34, 800-808 (2010).

- This study developed a quantitative pyrosequencing assay for the determination of ZAP-70 methylation adapted for routine use.

15. Kulis M, Heath S, Bibikova M et al. Epigenomic analysis detects widespread gene-body DNA hypomethylation in chronic lymphocytic leukemia. Nat. Genet. 44, 1236-1242 (2012).

16. Campo E, Swerdlow SH, Harris NL et al. The 2008 WHO classification of lymphoid neoplasms and beyond: evolving concepts and practical applications. Blood 117(19), 5019-5032 (2011).

- The World Health Organization classification of lymphoid neoplasms update in 2008 represents a worldwide consensus on the diagnosis of these tumors using a multidisciplinary approach. 
17. Chen YH, Peterson LC, Dittmann D et al. Comparative analysis of flow cytometric techniquesin assessment of ZAP-70 expression in relation to IgVH mutational status in chronic lymphocytic leukemia. Am. J. Clin. Pathol. 127, 182-191 (2007).

18. Dewald G, Brockman S, Paternoster $S$ et al. Chromosome anomalies detected by interphase fluorescence in situ hybridization: correlation with significant biological features of chronic lymphocytic leukemia. Br. J. Haematol. 121, 287-295 (2003).

19. Chan YH. Biostatistics102: quantitative data - parametric \& non-parametric tests. Singapore Med. J. 44(8), 391-396 (2003a).

20. Chan YH. Biostatistics 103: qualitative data -tests of independence. Singapore Med. J. 44(10), 498-503 (2003b).

21. QIAGEN. Pyromark-cpg-assays, human ITGA4 product GeneGlobe specification (2019). https://geneglobe.qiagen.com/search/?cat=\&q=ITGA4

22. Strati P, Parikh SA, Chaffee KG et al. CD49d associates with nodal presentation and subsequent development of lymphadenopathy in patients with chronic lymphocytic leukaemia. British J. Haematol. 178(1), 99-105 (2017).

- Authors investigated the association between CD49d expression and nodal disease at the time of presentation in patients with newly diagnosed CLL.

23. Hartmann TN, Grabovsky V, Wang W et al. Circulating B-cell chronic lymphocytic leukemia cells display impaired migration to lymph nodes and bone marrow. Cancer Res. 69(7), 3121-3130 (2009).

24. Mikeska T, Bock C, Do H et al. DNA methylation biomarkers in cancer: progress towards clinical implementation. Expert Rev. Mol. Diagn. 12, 473-487 (2012).

25. Ma Y, Wang X, Jin H. Methylated DNA and microRNA in body fluids as biomarkers for cancer detection. Int. J. Mol. Sci. 14, 10307-10331 (2013).

26. Medina-Rivera A, Santiago-Algarra D, Puthier D, Spicuglia S. Widespread enhancer activity from core promoters. Trends Biochem. Sci. 43, 452-468 (2018).

27. Mansouri L, Wierzbinska JA, Plass C, Rosenquist R. Epigenetic deregulation in chronic lymphocytic leukemia: clinical and biological impact. Semin. Cancer Biol. 51, 1-11 (2018).

28. Xanthopoulos C, Kostareli E. Advances in epigenetics and epigenomics in chronic lymphocytic leukemia. Curr. Genet. Med. Rep. 7 , 214-226 (2019).

29. Issa JP. Aging and epigenetic drift: a vicious cycle. J. Clin. Invest. 124, 24-29 (2014).

30. Teschendorff AE, Menon U, Gentry-Maharaj A et al. Age-dependent DNA methylation of genes that are suppressed in stem cells is a hallmark of cancer. Genome Res. 20, 440-446 (2010). 